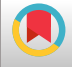

\title{
Rotavirus-Induced Diarrhea Changes the Proteins, Amino Acids and Fatty Acids Profiles in Fecal Samples of the Infants
}

\author{
Peng Fei ${ }^{1,2}$, Junliang Chen ${ }^{1}$, Yichao Jiang ${ }^{3}$, Hongjian Bai $^{3}$, Yanyan Wang ${ }^{3}$, Ying Han ${ }^{4}$, Min Xing ${ }^{1,2}$ and \\ Ling Guo ${ }^{3, *}$
}

${ }^{1}$ College of Food and Bioengineering, Henan University of Science and Technology, Luoyang, China

${ }^{2}$ International Joint Laboratory of Green Food Processing and Quality and Safety Control of Henan Province, Henan University of Science and Technology, Luoyang, China

${ }^{3}$ Key Lab of Dairy Science, Ministry of Education, College of Food Science, Northeast Agricultural University, Harbin, China

${ }^{4}$ Harbin Children's Hospital, Harbin, China

"Corresponding author: Key Laboratory of Dairy Science, College of Food Science and Engineering, Northeast Agricultural University, 59 Mucai Road, Harbin 150030 , Heilongjiang Province, People’s Republic of China. Tel: +86-45155190459, Fax: +86-45155190577, Email: guoling@neau.edu.cn

Received 2019 December 09; Revised 2020 March 20; Accepted 2020 July 16.

\begin{abstract}
Background: Rotavirus-induced diarrhea (RD) could cause disorders in food protein and fat metabolism of infants the changes of which have not been clearly revealed; however, relevant studies are limited.

Objectives: The aim was to investigate the changes of proteins, amino acids and fatty acids profiles in fecal samples of the infants caused by RD.

Methods: A total of 30 fecal samples were collected from $15 \mathrm{RD}$ infants and 15 healthy infants. The compositions of fecal proteins, amino acids and fatty acids profiles in all fecal samples were analyzed using sodium dodecyl sulfate polyacrylamide gel electrophoresis (SDS-PAGE), automatic amino acid analyzer and gas chromatography (GC), respectively.

Results: Compared to H infants, the feces in RD infants had lower contents of proteins with 50 - 55, 79 - 80, and 84 - $85 \mathrm{KDa}$, meanwhile higher contents of proteins with 67 - $69 \mathrm{KDa}$. The levels of aspartic acid, threonine, serine, glutamic acid, glycinc, alanine, valine, methionine, isoleucine, leucine, lysine, phenylalanine, histidine, arginine, and proline in the feces from RD infants were significantly lower than that of $\mathrm{H}$ infants $(\mathrm{P}<0.05)$. The relative proportions of butyric acid, elaidic acid, linoleic acid, cis-11, 14-icotenic acid, cis-11, 14, 17- epoxyeicosatrienoic acids, cis-13, 16-docosanoic acid, and cis-7, 10, 13, 16,19 docosapentaenoic acid in feces from RD infants decreased significantly compared to those of $\mathrm{H}$ infants $(\mathrm{P}<0.05)$. On the contrary, significant increases in the relative proportions of caprylic acid, decanoic acid, undecanoic acid, lauric acid, tridecanoic acid, myristic acid, myristoleic acid, palmitic acid, cis-10-heptadecaenoic acid, oleic acid, and $\gamma$-linoleic acid were found in the; feces of RD infants $(\mathrm{P}<.05)$.

Conclusions: RD changed the proteins, amino acids, and fatty acids profiles in infants feces, which improved the understanding of relationship between $\mathrm{RD}$ and fecal metabolites profile.
\end{abstract}

Keywords: Rotavirus-Induced Diarrhea, Feces, Proteins, Amino Acids, Fatty Acids, Infants

\section{Background}

Rotavirus-induced diarrhea (RD) is the leading cause of severe diarrhea in young children and infants (1). An estimated 2.3 million hospitalizations and approximately 527000 deaths in children aged $<5$ years are caused by rotavirus annually worldwide (2). The diarrhea in human is associated with the dysfunction of intestinal mucosal cell absorption, resulting in the intestinal microecological imbalance and changes in composition of fecal metabolites $(3,4)$. Previous studies have revealed the changes in fecal microbiota of infants and children infected with $\operatorname{RD}(5,6)$. However, reports on the differences in the fecal metabo- lites profile between the RD infants and healthy $(\mathrm{H})$ infants are limited.

Among many fecal metabolites, the changes in fecal amino acids (AAs) and fatty acids (FAs) contributed to reveal the relationship between intestinal diseases and fecal metabolites profile $(7,8)$. On the one hand, fecal proteins profile has been reported to be affected by intestinal diseases, and the significant differences in composition of fecal proteins have been found in patients suffering from intestinal disease, such as a significant increase of calprotectin and lactoferrin in feces of patients with inflammatory bowel disease $(9,10)$. Meanwhile, as an important metabolite of protein metabolism, a range of fecal 
AAs levels were up-regulated or down-regulated due to the effects of intestinal diseases, which improved the understanding of changes in protein metabolism under the influence of intestinal diseases $(11,12)$. On the other hand, the composition of fecal FAs containing short-chain fatty acids (SCFAs), medium-chain fatty acids (MCFAs), and long-chain fatty acids (LCFAs) have also been altered due to inflammation or diarrhea (13-15). Huda-Faujan et al. (13) revealed that inflammatory bowel disease leads to the decrease of acetic acid, butyric acid and propionic acid, and increase of lactic and pyruvic acids in; feces. De et al. (14) found the levels of fecal MCFs of patients with inflammatory bowel disease decreased significantly, such as pentanoate, hexanoate, heptanoate, octanoate and nonanoate. Yoshioka et al. (15) reported that intestinal secretion induced by cholera toxin might delay the mucosal uptake and lymphatic transport of LCFs, and the amount of linoleic acid transported into the intestinal lymph was delayed and reduced in cholera toxin-treated rats. Therefore, in order to understand fully the pathological characteristics of RD infants, the changes in compositions of fecal proteins, AAs and FAs between RD infants and $\mathrm{H}$ infants should be elucidated.

In this study, fecal samples were collected from $15 \mathrm{RD}$ infants and $15 \mathrm{H}$ infants. All infants were given equal amounts of breast milk and complementary foods. The differences in proteins, AAs, and FAs profiles in fecal samples between $\mathrm{RD}$ infants and $\mathrm{H}$ infants were analyzed to deepen the understanding of relationship between $\mathrm{RD}$ and fecal metabolites profile.

\section{Objectives}

The thirty fecal samples used in this study were collected at a period from November 2018 to February 2019, among them, fifteen fecal samples were obtained from the RD infants (mean age 6.8 months old; range 4 - 9 months old; sex ratio 1:1), who were officially diagnosed as RD patients by the Harbin Children's Hospital using specific enzyme immunoassay method (6). Other 15 fecal samples were collected from the $\mathrm{H}$ infants ranging 4 to 9 months old (mean 6.8 months; sex ratio 1:1) were provided by volunteers in Harbin city. All infants were provided with the same diet, including equal amounts of breast milk, fruit puree, and rice flour. All fecal samples after collection were transferred into sterile plastic tubes, immediately dispatched to the laboratory where the study was conducted, and then stored at $-80^{\circ} \mathrm{C}$ before use. In addition, this study was approved by the local ethics committee, and "freely given informed consent" was signed by parents of all infants.

\section{Methods}

\subsection{Composition Assays of Fecal Proteins}

Approximately $100 \mathrm{mg}$ fecal samples (wet weight) were transferred to a sterilized centrifuge tube, followed by the addition of trifluoracetic acid $(0.15 \% \mathrm{v} / \mathrm{v})$ of $200 \mu \mathrm{L}$ and a gently mixing. All samples were centrifuged at 13,000 rpm for $5 \mathrm{~min}$ at $4^{\circ} \mathrm{C}$ using a refrigerating centrifuge (Heraeus, Hanau, Germany) to obtain fecal supernatants (16). The supernatants of $10 \mu \mathrm{L}$ were heated at $95^{\circ} \mathrm{C}$ for $10 \mathrm{~min}$, and analyzed with Sodium dodecyl sulfate-polyacrylamide gel electrophoresis (SDS-PAGE) using 5\% stacking gel and 12\% separating gel respectively and the Coomassie brilliant blue $\mathrm{R}$ 250C staining (17). The gels were scanned with an HP scanner (HP1000, USA) to obtain corresponding images of protein bands. After that, the fecal protein feature was analyzed using a relative ratio analysis with Scion image PC software (Scion Co, Frederisk, USA) (18).

\subsection{Assays of Fecal Amino Acids Profile}

Fecal samples of $1 \mathrm{~g}$ (wet weight) were weighed and transferred to a hydrolysis tube. $6 \mathrm{~mol} / \mathrm{L} \mathrm{HCl}$ of $13 \mathrm{~mL}$ and 3 drops of phenol were added to the fecal samples followed by a vacuum treatment with $99.99 \%$ nitrogen. The hydrolysis tube was kept at $110^{\circ} \mathrm{C}$ for $22 \mathrm{~h}$ in a thermoelectric thermostat drying box to obtain the fecal hydrolysate. After filtration, fecal hydrolysate of $1 \mathrm{~mL}$ was dried with vacuum condition at $45^{\circ} \mathrm{C}$, and then dissolved in $1 \mathrm{~mL}$ of citrate buffer ( $\mathrm{pH}$ 2.2). Finally, the types and contents of fecal AAs were determined with external standard method using an automatic amino acid analyzer (Hitachi, L-8900, Tokyo, Japan) (19).

\subsection{Assays of Fecal Fatty Acids Profile}

Approximately $100 \mathrm{mg}$ (wet weight) fecal samples weighed and etherified with boron fluoride methanol methyl esterification method reported by Lópezlópez et al. (20). The supernatant containing methyl FAs was analyzed by high performance gas chromatography (HPGC) using Agilent 7890A gas chromatograph (Palo Alto, USA) to determine the relative amount of FAs in; feces.

\subsection{Statistical Analysis}

Each trial was independently carried out in triplicate. The data were analyzed by two-tailed Student's t-test to compare two groups using SPSS 20.0 software (SPSS, Inc., Chicago, IL, USA). The data were expressed as mean values \pm standard deviations. The level of statistical significance was set at $\leq 0.05$ for all analyses. 


\section{Results}

The gel bands representing fecal proteins from RD infants and fifteen $\mathrm{H}$ infants are presented according to SDSPAGE results (Figure 1). Using a relative ratio analysis by Scion image PC software, the relative proportion of each band was determined according to its brightness (Table 1). The results showed that all bands were divided into 17 groups based on the molecular weight of proteins, among them, significant differences $(\mathrm{P}<0.05)$ in relative proportions of fecal proteins were found in four groups, including 50 - $55 \mathrm{KDa}, 67$ - $69 \mathrm{KDa}, 79$ - $80 \mathrm{KDa}$, and 84 - $85 \mathrm{KDa}$. In addition, compared to $\mathrm{H}$ infants, the relative proportions of fecal proteins with 50 - $55 \mathrm{KDa}, 79$ - $80 \mathrm{KDa}$, and 84 - $85 \mathrm{KDa}$ from RD infants decreased significantly $(\mathrm{P}<0.05)$, meanwhile, the relative proportion of fecal proteins with $67-69$ KDa increased significantly $(\mathrm{P}<0.05)$.

Almost all sort of amino acids of infants; feces from $\mathrm{RD}$ and $\mathrm{H}$ samples were also assayed (Table 2). The results showed that RD infants; feces were detected to have decreased levels of the AAs (aspartic acid, threonine, serine, glutamic acid, glycinc, alanine, valine, methionine, isoleucine, leucine, lysine, phenylalanine, histidine, argi-

\begin{tabular}{|c|c|c|}
\hline \multirow{2}{*}{$\begin{array}{l}\text { Protein Molecular } \\
\text { Weight (KDa) }\end{array}$} & \multicolumn{2}{|c|}{ Relative Proportion (\%) } \\
\hline & RD Group & H Group \\
\hline $150-160$ & $12.09 \pm 2.45^{\mathrm{A}}$ & $14.23 \pm 3.83^{\mathrm{A}}$ \\
\hline $140-150$ & $7.07 \pm 4.27^{\mathrm{A}}$ & $5.03 \pm 2.15^{\mathrm{A}}$ \\
\hline $84-85$ & $10.88 \pm 5.38^{A}$ & $0^{\mathrm{B}}$ \\
\hline $79-80$ & $7.70 \pm 4.33^{\mathrm{A}}$ & $1.47 \pm 0.25^{\mathrm{B}}$ \\
\hline $67-69$ & $0^{\mathrm{A}}$ & $8.25 \pm 2.05^{\mathrm{B}}$ \\
\hline $58-66$ & $19.51 \pm 5.72^{\mathrm{A}}$ & $11.67 \pm 7.77^{\mathrm{A}}$ \\
\hline $50-55$ & $6.55 \pm 1.77^{\mathrm{A}}$ & $0^{\mathrm{B}}$ \\
\hline $43-44$ & $6.20 \pm 1.21^{\mathrm{A}}$ & $8.42 \pm 2.12^{\mathrm{A}}$ \\
\hline $42-43$ & $11.46 \pm 2.05^{\mathrm{A}}$ & $7.68 \pm 1.34^{\mathrm{A}}$ \\
\hline $39-41$ & $17.19 \pm 6.93^{A}$ & $16.42 \pm 4.46^{\mathrm{A}}$ \\
\hline 37-39 & $10.02 \pm 4.87^{\mathrm{A}}$ & $10.21 \pm 4.00^{\mathrm{A}}$ \\
\hline $35-37$ & $6.55 \pm 2.03^{A}$ & $5.16 \pm 1.64^{A}$ \\
\hline $33-35$ & $6.60 \pm 1.76^{\mathrm{A}}$ & $9.76 \pm 2.65^{\mathrm{A}}$ \\
\hline $30-31$ & $8.75 \pm 6.92^{A}$ & $6.23 \pm 3.82^{\mathrm{A}}$ \\
\hline $22-26$ & $22.60 \pm 11.11^{\mathrm{A}}$ & $29.12 \pm 11.94^{\mathrm{A}}$ \\
\hline 19-20 & $14.35 \pm 9.41^{\mathrm{A}}$ & $10.57 \pm 4.34^{\mathrm{A}}$ \\
\hline $14-16$ & $10.48 \pm 5.60^{\mathrm{A}}$ & $12.75 \pm 0.30^{\mathrm{A}}$ \\
\hline
\end{tabular}

${ }^{\text {a }}$ Superscripts with different capital letters within the same row are significantly different $(\mathrm{P}<0.05)$.
Table 2. Differences in Levels of Fecal Amino Acids Between RD Infants and H Infants

\begin{tabular}{|c|c|c|}
\hline \multirow{2}{*}{ Amino Acid Ingredient } & \multicolumn{2}{|c|}{ Levels (mg/100 mg) } \\
\hline & RD Group & H Group \\
\hline Aspartic acid & $0.288 \pm 0.158^{\mathrm{A}}$ & $0.561 \pm 0.190^{\mathrm{B}}$ \\
\hline Threonine & $0.244 \pm 0.119^{A}$ & $0.463 \pm 0.174^{\mathrm{B}}$ \\
\hline Serine & $0.208 \pm 0.117^{\mathrm{A}}$ & $0.374 \pm 0.133^{\mathrm{B}}$ \\
\hline Glutamic acid & $0.457 \pm 0.261^{\mathrm{A}}$ & $0.766 \pm 0.260^{\mathrm{B}}$ \\
\hline Glycinc & $0.149 \pm 0.085^{\mathrm{A}}$ & $0.275 \pm 0.098^{\mathrm{B}}$ \\
\hline Alanine & $0.194 \pm 0.106^{\mathrm{A}}$ & $0.380 \pm 0.116^{\mathrm{B}}$ \\
\hline Cystine & $0.147 \pm 0.057^{\mathrm{A}}$ & $0.189 \pm 0.063^{\mathrm{A}}$ \\
\hline Valine & $0.271 \pm 0.111^{\mathrm{A}}$ & $0.430 \pm 0.108^{B}$ \\
\hline Methionine & $0.224 \pm 0.134^{\mathrm{A}}$ & $0.440 \pm 0.242^{\mathrm{B}}$ \\
\hline Isoleucine & $0.131 \pm 0.076^{\mathrm{A}}$ & $0.223 \pm 0.079^{B}$ \\
\hline Leucine & $0.244 \pm 0.137^{\mathrm{A}}$ & $0.421 \pm 0.155^{\mathrm{B}}$ \\
\hline Tyrosine & $0.097 \pm 0.420^{\mathrm{A}}$ & $0.137 \pm 0.077^{A}$ \\
\hline Phenylalanine & $0.179 \pm 0.077^{\mathrm{A}}$ & $0.258 \pm 0.082^{\mathrm{B}}$ \\
\hline Lysine & $0.218 \pm 0.169^{A}$ & $0.354 \pm 0.175^{\mathrm{B}}$ \\
\hline Histidine & $0.087 \pm 0.041^{\mathrm{A}}$ & $0.126 \pm 0.047^{\mathrm{B}}$ \\
\hline Arginine & $0.118 \pm 0.073^{A}$ & $0.254 \pm 0.096^{\mathrm{B}}$ \\
\hline Proline & $0.171 \pm 0.078^{A}$ & $0.288 \pm 0.136^{\mathrm{B}}$ \\
\hline Isoleucine & $0.131 \pm 0.076^{\mathrm{A}}$ & $0.223 \pm 0.079^{B}$ \\
\hline Leucine & $0.244 \pm 0.137^{\mathrm{A}}$ & $0.421 \pm 0.155^{\mathrm{B}}$ \\
\hline
\end{tabular}

nine, and proline) when compared to healthy subjects; feces $(\mathrm{P}<0.05)$.

The compositions of fecal FAs of RD infants and $\mathrm{H}$ infants were analyzed. Compared to $\mathrm{H}$ infants, the relative proportions of butyric acid (C4:0), elaidic acid (C18:1N9T), linoleic acid (C18:2N6C), cis-11, 14-icotenic acid (C22:0), cis11, 14, 17- epoxyeicosatrienoic acid (C20:3N3), cis-13, 16docosanoic acid (C22:2), and cis-7, 10, 13, 16,19 docosapentaenoic acid (C20:5N3) in; feces from RD infants decreased significantly $(\mathrm{P}<0.05)$. The significant increases in the relative proportions of caprylic acid (C8:0), decanoic acid (C10:0), undecanoic acid (C11:0), lauric acid (C12:0), tridecanoic acid (C13:0), myristic acid (C14:0), myristoleic acid (C14:0), palmitic acid (C16:0), cis-10-heptadecaenoic acid (C17:1), oleic acid (C18:1N9C), and $\gamma$-linoleic acid (C18:3N6) were found in the; feces collected from $\mathrm{RD}$ infants $(\mathrm{P}<$ 0.05) (Table 3). 


\section{A}

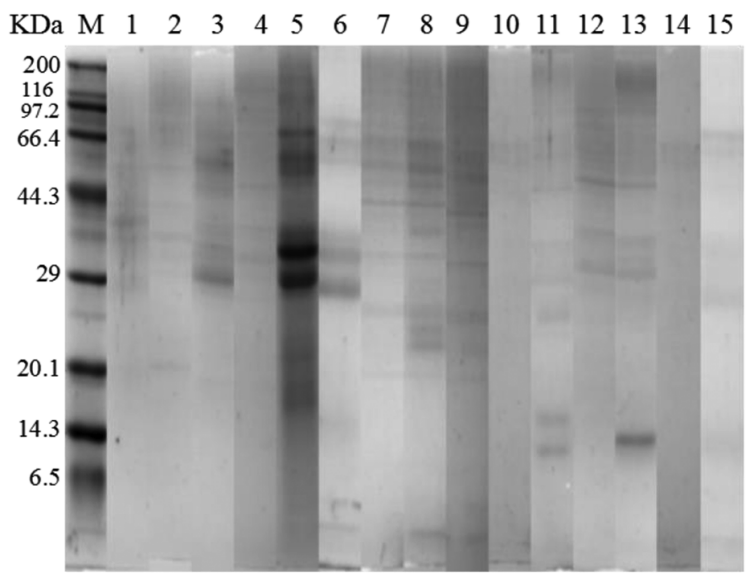

B

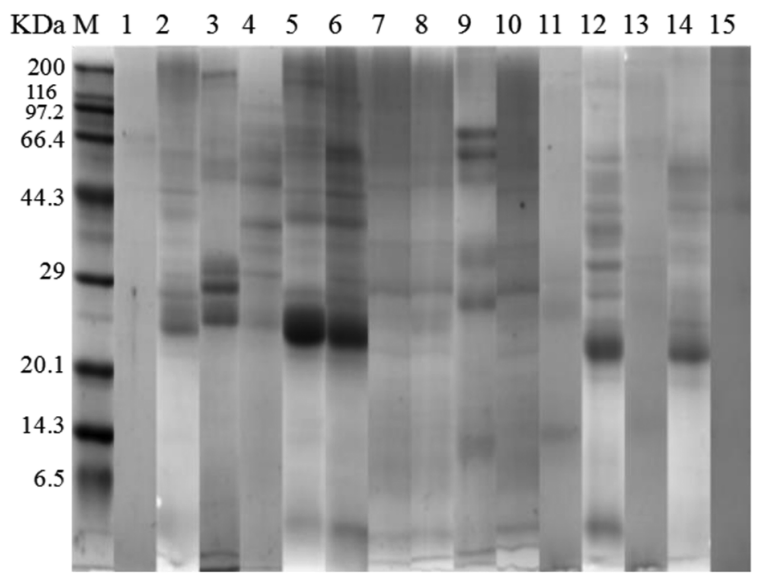

Figure 1. SDS-PAGE analysis of fecal proteins of 30 infants. (A) Lane M: marker, Lanes 1-15: RD infants (B) Lane M: marker, Lanes 1-15: H infants.

\section{Discussion}

Protein metabolism could be affected by the intestinal mucosal damage caused by microbial dysbiosis, diarrhea and other intestinal deseases, leading to the changes in composition of proteins in feces $(16,21)$. Among them, alpha-1-antitrypsin in human milk could withstand the breakdown of digestive juices, and help the survival of other proteins especially during bacterial diarrhea (22). Increased fecal lactoferrin can be a significant indicator for monitoring intestinal inflammation in children with non-virus diarrhea (23). In addition, serum albumin was identified as a marker in the colorectal cancer, meanwhile, polymeric-immunoglobulin receptor could not protect rotavirus from expanding in the gut $(16,24)$. Similarly, after infants suffered from $\mathrm{RD}$, the relative proportions of fecal proteins with 50-55 KDa, 79-80 KDa, and 84 - $85 \mathrm{KDa}$ decreased significantly $(\mathrm{P}<0.05)$, meanwhile, the relative proportion of fecal proteins with 67-69 KDa increased significantly $(\mathrm{P}<0.05)$. Given that all fecal proteins from infants in the study were derived from breast milk, it was reasonable to infer these differential proteins should correspond to polymeric immunoglobulin receptor (84 KDa), lactoferrin (80 KDa), serum albumin (69 KDa) and alpha-1antitrypsin ( $53 \mathrm{KDa}$ ) according to the molecular weight of the proteins $(10,22,25,26)$. However, a deeper and more comprehensive study on the relationship between differential proteins and rotavirus infection is still needed in future.

As the structural units for proteins and polypeptide, AAs were participated in synthesis of bioactive molecules which played the key role in the regulation of signaling pathways and metabolism (27). AAs metabolism in complex gut environment provides a strategy for bacteria survival and growth with both positive and negative effects on host (28). For example, Marchesi et al reported the AAs degradation of inflammatory bowel disease (IBD) patients were promoted due to an impairment of the metabolic activity of the gut bacteria (29), meanwhile, De et al found a higher AAs level in the; feces of IBD patients, and considered it was because that inflammatory conditions induce large energy requirements to repair the damaged mucosa leading to enhanced protein catabolism (30). Besides, Bjerrum et al revealed that the levels of aspartic acid and glutamate in fecal extracts from inactive Crohn's disease (CD) patients were significantly reduced compared with those of healthy samples (11). Our results showed that there were significant decreases in AAs levels in; feces of RD infants, including aspartic acid, threonine, serine, glutamic acid, glycinc, alanine, valine, methionine, isoleucine, leucine, phenylalanine, lysine, histidine, arginine, and proline, which suggested a reduced level of AAs in; feces linked to the diarrhea induced by rotavirus defection.

In previous studies, as the significant metabolite of intestinal microbiota, the changes in levels of SCFAs in; feces of diarrhea patients have been a focus of research (31, 32). However, intestinal diseases can not only change the diversity of intestinal microbiota, but also cause intestinal metabolic disorders. Therefore, it is necessary to conduct a comprehensive analysis on the differences in fecal FAs profile consisting of SCFAs, MCFAs and LCFAs between RD infants and $\mathrm{H}$ infants.

Butyric acid was considered as one of the most im- 


\begin{tabular}{|c|c|c|}
\hline \multirow{2}{*}{ Fatty Acid Ingredient } & \multicolumn{2}{|c|}{ Relative Proportion (\%) } \\
\hline & RD Group & H Group \\
\hline Butyric acid (C4:0) & $6.322 \pm 1.101^{\mathrm{A}}$ & $9.241 \pm 1.950^{\mathrm{B}}$ \\
\hline Caprylic acid (C8:0) & $0.753 \pm 0.106^{A}$ & $0^{\mathrm{B}}$ \\
\hline Decanoic acid (C10:0) & $0.691 \pm 0.150^{\mathrm{A}}$ & $0.244 \pm 0.118^{\mathrm{B}}$ \\
\hline Undecanoic acid (C11:0) & $0.380 \pm 0.084^{\mathrm{A}}$ & $0^{\mathrm{B}}$ \\
\hline Lauric acid (C12:0) & $6.431 \pm 1.701^{\mathrm{A}}$ & $1.336 \pm 0.142^{\mathrm{B}}$ \\
\hline Tridecanoic acid (C13:0) & $0.340 \pm 0.106^{A}$ & $0^{\mathrm{B}}$ \\
\hline Myristic acid (C14:0) & $11.862 \pm 7.845^{\mathrm{A}}$ & $3.783 \pm 0.674^{\mathrm{B}}$ \\
\hline Myristoleic acid (C14:1) & $0.331 \pm 0.177^{A}$ & $0^{\mathrm{B}}$ \\
\hline Pentadecanoic acid (C15:0) & $0.837 \pm 0.310^{\mathrm{A}}$ & $0.893 \pm 0.327^{\mathrm{A}}$ \\
\hline Palmitic acid (C16:0) & $32.727 \pm 3.219^{A}$ & $19.596 \pm 3.150^{\mathrm{B}}$ \\
\hline Palmitoleic acid C (16:1) & $1.293 \pm 0.504^{\mathrm{A}}$ & $1.191 \pm 0.555^{\mathrm{A}}$ \\
\hline Heptadecanoic acid (C17:0) & $1.255 \pm 0.971^{\mathrm{A}}$ & $1.739 \pm 0.686^{\mathrm{A}}$ \\
\hline Cis-10-heptadecaenoic acid (C17:1) & $0.355 \pm 0.313^{A}$ & $0^{\mathrm{B}}$ \\
\hline Stearic acid (C18:0) & $23.598 \pm 5.804^{\mathrm{A}}$ & $20.369 \pm 5.954^{\mathrm{A}}$ \\
\hline Elaidic acid (C18:1N9T) & $0.228 \pm 0.067^{\mathrm{A}}$ & $7.63 \pm 2.076^{\mathrm{B}}$ \\
\hline Oleic acid (C18:1N9C) & $21.468 \pm 5.080^{A}$ & $11.977 \pm 4.783^{\mathrm{B}}$ \\
\hline Linoleic acid (C18:2N6C) & $14.45 \pm 9.581^{\mathrm{A}}$ & $29.798 \pm 22.075^{\mathrm{B}}$ \\
\hline Arachidic acid (C20:0) & $1.612 \pm 0.487^{\mathrm{A}}$ & $1.114 \pm 0.279^{\mathrm{A}}$ \\
\hline$\gamma$-linoleic acid (C18:3N6) & $0.058 \pm 0.031^{\mathrm{A}}$ & $0^{\mathrm{B}}$ \\
\hline Cis-11-ethylenic acid (C20:1) & $1.527 \pm 0.441^{\mathrm{A}}$ & $1.249 \pm 0.998^{A}$ \\
\hline$\alpha$-linoleic acid (C18:3N3) & $1.592 \pm 0.322^{\mathrm{A}}$ & $1.348 \pm 0.752^{\mathrm{A}}$ \\
\hline Heneicosanoic acid (C21:0) & $0.321 \pm 0.105^{\mathrm{A}}$ & $0.338 \pm 0.205^{\mathrm{A}}$ \\
\hline Cis-11,14-icotenic acid (C20:2) & $0.658 \pm 0.251^{\mathrm{A}}$ & $3.023 \pm 0.929^{\mathrm{B}}$ \\
\hline Behenic acid (C22:0 & $1.034 \pm 0.872^{\mathrm{A}}$ & $0.955 \pm 0.273^{\mathrm{A}}$ \\
\hline Cis-8,11,14-epoxyeicosatrienoic acids (C23:6) & $0.437 \pm 0.396^{\mathrm{A}}$ & $0.598 \pm 0.386^{\mathrm{A}}$ \\
\hline Erucic acid (C22:1N9) & $0.511 \pm 0.171^{\mathrm{A}}$ & $0.956 \pm 0.333^{\mathrm{A}}$ \\
\hline Cis-11,14,17-epoxyeicosatrienoic acids (C20:3N3) & $0^{\mathrm{A}}$ & $0.602 \pm 0.367^{\mathrm{B}}$ \\
\hline Arachidonic acid (C20:4N6) & $2.235 \pm 2.013^{\mathrm{A}}$ & $3.177 \pm 0.884^{\mathrm{A}}$ \\
\hline Cis-13, 16- docosanoic acid (C22:2) & $0^{\mathrm{A}}$ & $2.294 \pm 0.798^{\mathrm{B}}$ \\
\hline Lignoceric acid (C24:0) & $0.625 \pm 0.473^{\mathrm{A}}$ & $1.06 \pm 0.055^{\mathrm{A}}$ \\
\hline Cis-7,10,13,16,19-docosapentaenoic acid (C20:5N3) & $0^{\mathrm{A}}$ & $7.068 \pm 4.510^{\mathrm{B}}$ \\
\hline Nervonic acid C24:1 & $0.362 \pm 0.220^{\mathrm{A}}$ & $0.454 \pm 0.362^{A}$ \\
\hline Cis-4,7,10,13,16,19-docosahexaenoic acid (C22:6N3) & $0.918 \pm 0.881^{\mathrm{A}}$ & $1.041 \pm 0.506^{\mathrm{A}}$ \\
\hline
\end{tabular}

${ }^{\mathrm{a}}$ Superscripts with different capital letters within the same row are significantly different $(\mathrm{P}<0.05)$.

portant SCFAs associated with human health, and could be produced by metabolism of intestinal microorganisms; therefore, the differences in biodiversity of fecal microbiota can explain the possible reason for butyric acid alteration of patients with intestinal diseases (33).
Some researchers suggested that the lower levels of butyrate and propionate in; feces of $\mathrm{CD}$ and ulcerative colitis (UC) diarrhea patients should be the consequence of an inflammation-driven intestinal dysbiosis (11). Further, De et al found the depletion of butyric acid in feces of 
IBD patients was linked to a shift in the composition and metabolic activity of colonic microbiota (30). In this study, the level of butyric acid in; feces of infants decreased significantly after infection with rotavirus, which was similar to the study reported by Canani et al. who found a significant reduction in the concentration of fecal butyric acid of patients with intestinal diseases (34). However, in our previous report, we detected formic acid, acetic acid, propionic acid and butyric acid in the feces of RD and $\mathrm{H}$ infants who were between 0 and 6 months old, among them, acetic acid was the dominant SCFA (35), while, in current study, only butyric acid was detected in the feces of RD and $\mathrm{H}$ infants who were between 4 and 9 months old. In addition, there was no significant difference in the levels of these five SCFAs in the feces between 0-6-month-old infants with and without RD (35), on the contrary, the level of butyric acid in $\mathrm{RD}$ infants was significantly reduced compared to $\mathrm{H}$ infants in this study. Since the infants in the two studies had the same diet, the difference in SCFAs should be due to the age, in particular, the intestinal flora of infants younger than 1 year old is a dynamic colonization, which suggests that a more detailed age division should be made in the clinical analysis of RD infants in order to implement specific treatment measures for patients of different ages.

In prior study, MCFAs were found to be significantly reduced in the; feces of patients with $\mathrm{CD}$, UC and pouchitis, and were used as a class of metabolic biomarkers of disease-related changes (36). Garner et al also found a lower prevalence of some MCFs in patients with UC than that in asymptomatic individuals (37). Similarly, in this study, the significant decreases in relative proportions of MCFAs and LCFAs, such as C18:1N9T, C18:2N6C, C22:0, C20:3N3, C22:2, and C20:5N3 in; feces from RD infants were found in; feces of RD infants. Furthermore, the relative proportions of C8:0, C10:0, C11:0, C12:0, C13:0, C14:1, C14:0, C16:0, C17:1, C18:1N9C, and C18:3N6 were increased in the; feces from RD infants, which indicated that RD may affect the absorption of the above fatty acids. Thus, in addition to SCFAs, the metabolic profiles of MCFAs and LCFAs should also be analyzed as an important prospective longitudinal study.

In summary, we provided a comprehensive analysis to illustrate the effects of $\mathrm{RD}$ on protein, AAs and fat metabolism. The data of this study revealed the differences in compositions of fecal proteins, AAs and FAs (SCFAs, MCFs, and LCFs) between RD infants and $\mathrm{H}$ infants. These findings revealed the pathological characteristics of RD in infants, and expanded the understanding on relationship between RD and fecal metabolites profile.

\section{Footnotes}

Authors' Contribution: Ling Guo and Peng Fei were responsible for the whole experiment and the writing of the paper. Junliang Chen and Yichao Jiang were responsible for the implementation of the experiment. Yanyan Wang and Min Xing provided some help for data analysis. Hongjian Bai and Yin Han was responsible for the collection of the fecal samples.

\section{Conflict of Interests: None.}

Ethical Approval: This study was approved by the local ethics committee, and "freely given informed consent" was signed by parents of all infants.

Funding/Support: This research was supported by the Doctor Scientific Research Start-up Fund of Henan University of Science and Technology (13480066), the national natural science foundation of China (31501511 and $31601450)$, research project of science and technology of the Heilongjiang province (12541026), and Youth Talent Support Project of Henan Province (2020HYTP029).

\section{References}

1. Tate JE, Burton AH, Boschi-Pinto C, Parashar UD, World Health Organization-Coordinated Global Rotavirus Surveillance N. Global, regional, and national estimates of rotavirus mortality in children $<5$ years of age, 2000-2013. Clin Infect Dis. 2016;62 Suppl 2:S96-S105. doi: 10.1093/cid/civ1013. [PubMed: 27059362].

2. Desselberger U. Rotaviruses. Virus Res. 2014;190:75-96. doi: 10.1016/j.virusres.2014.06.016. [PubMed: 25016036].

3. Mattos AP, Riberio TCM, Mendes PSA, Valois SS, Mendes CMC, Riberio HC. Comparison of yogurt, soybean, casein, and amino acid-based diets in children with persistent diarrhea. Nutr Res. 2009;29(7):462-9. doi:10.1016/j.nutres.2009.06.005. [PubMed: 19700033].

4. Kim AS, Hwang J. The dietary therapy and use of probiotics in the treatment of pediatric acute diarrhea. J Korean Med Assoc. 2012;55(6):532. doi: 10.5124/jkma.2012.55.6.532.

5. Solano-Aguilar G, Fernandez KP, Ets H, Molokin A, Vinyard B, Urban JF, et al. Characterization of fecal microbiota of children with diarrhea in 2 locations in Colombia.JPediatr Gastroenterol Nutr. 2013;56(5):50311. doi: 10.1097/MPG.ob013e318282aa12. [PubMed: 23254448].

6. Fei P, Li L, Cai XL, Zhang XJ, Bai HJ, Jiang YJ, et al. Differences in the biodiversity of the fecal microbiota of infants with rotaviral diarrhea and healthy infants. Jundishapur J Microbiol. 2016;9(4). e32356. doi: 10.5812/jjm.32356. [PubMed: 27279991]. [PubMed Central: PMC4895788].

7. Kocsis D, Papp M, Tornai T, Tulassay Z, Herszenyi L, Toth M, et al. Intestinal fatty acid binding protein: marker of enterocyte damage in acute and chronic gastroenterological diseases. Orv Hetil. 2016;157(2):59-64. doi: 10.1556/650.2016.30336. [PubMed: 26726140].

8. Dai J, Liu WZ, Zhao YQ, Hu YB, Ge ZZ. Relationship between fecal lactoferrin and inflammatory bowel disease. Scand J Gastroentero. 2007;42(12):1440-4. doi: 10.1080/00365520701427094. [PubMed: 17852860].

9. Waldmann TA. Protein-losing enteropathy and kinetic studies of plasma protein metabolism. Semin Nucl Med. 1972;2(3):251-63. doi: 10.1016/s0001-2998(72)80036-9. [PubMed: 4558062]. 
10. Wagner M, Peterson CG, Ridefelt P, Sangfelt P, Carison M. Fecal markers of inflammation used as surrogate markers for treatment outcome in relapsing inflammatory bowel disease. World J Gastroentero. 2008,14(36):5584-9. discussion 5588. doi: 10.3748/wjg.14.5584. [PubMed: 18810778]. [PubMed Central: PMC2746347].

11. Bjerrum JT, Wang YI, Hao F, Coskun M, Ludwig C, Gunther U, et al. Metabonomics of human fecal extracts characterize ulcerative colitis, Crohn's disease and healthy individuals. Metabolomics. 2015;11:122-33. doi: 10.1007/s11306-014-0677-3. [PubMed: 25598765]. [PubMed Central: PMC4289537].

12. Liu Y, Wang X, Hou Y, Yin Y, Qiu Y, Wu G, et al. Roles of amino acids in preventing and treating intestinal diseases: recent studies with pig models. Amino Acids. 2017;49(8):1277-91. doi: 10.1007/s00726-017-24501. [PubMed: 28616751].

13. Huda-Faujan N, Abdulamir AS, Fatimah AB, Muhammad AO Shuhaimi M, Yazid AM, et al. The impact of the level of the intestinal short chain fatty acids in inflammatory bowel disease patients versus healthy subjects. Open Biochem J. 2010;4:53-8. doi: 10.2174/1874091X01004010053. [PubMed: 20563285]. [PubMed Central: PMC2887640].

14. De Preter V, Machiels K, Joossens M, Arijs I, Matthys C, Vermeire S, et al. Faecal metabolite profiling identifies medium-chain fatty acids as discriminating compounds in IBD. Gut. 2015;64(3):447-58. doi: 10.1136/gutjnl-2013-306423. [PubMed: 24811995].

15. Yoshioka M, Asakura H, Miura S, Hamada Y, Kobayashi K, Morishita KT, et al. Malabsorption of long-chain fatty acid in cholera toxin-induced secretory diarrhea. Dig Dis Sci. 1986;31(5):519-23. doi: 10.1007/BF01320318. [PubMed: 3698768].

16. Ang CS, Rothacker J, Patsiouras H, Gibbs P, Burgess AW, Nice EC. Use of multiple reaction monitoring for multiplex analysis of colorectal cancer-associated proteins in human feces. Electrophoresis. 2011;32(15):1926-38. doi: 10.1002/elps.201000502. [PubMed: 21538981].

17. Dubrow R, Yannielli L. Fecal protein markers of colorectal cancer. Am J Gastroenterol. 1992;87(7):854-8. [PubMed: 1615938].

18. Onodera Y, Ono T, Nakasato K, Toda K. Homogeneity and microstructure of tofu depends on $11 \mathrm{~s} / 7 \mathrm{~s}$ globulin ratio in soymilk and coagulant concentration. Sci Technol Int. 2009;15(3):265-74. doi: 10.3136/fstr.15.265.

19. Ministry of Health of the People's Republic of China. Determination of amino acids in food. Beijing(China): Ministry of Health of the People's Republic of China; 2016. Available from: https://www.adaptationundp.org/partners/ministry-health-peoples-republic-china.

20. Lopez-Lopez A, Castellote-Bargallo AI, Lopez-Sabater MC. Comparison of two direct methods for the determination of fatty acids in infant feces. Anal Biochem. 2000;282(2):250-5. doi: 10.1006/abio.2000.4616. [PubMed: 10873281].

21. Caldeira RM, Belo AT, Santos CC, Vazques MI, Portugal AV. The effect of body condition score on blood metabolites and hormonal profiles in ewes. Small Rumin Res. 2007;68(3):233-41. doi: 10.1016/j.smallrumres.2005.08.027.

22. Chowanadisai W, Lonnerdal B. Alpha(1)-antitrypsin and antichymotrypsin in human milk: origin, concentrations, and stability. Am J Clin Nutr. 2002;76(4):828-33. doi: 10.1093/ajcn/76.4.828. [PubMed: 12324297].

23. Chen CC, Chang CJ, Lin TY, Lai MW, Chao HC, Kong MS. Usefulness of fecal lactoferrin in predicting and monitoring the clinical severity of infectious diarrhea. World J Gastroentero. 2011;17(37):4218-24. doi: 10.3748/wjg.v17.i37.4218. [PubMed: 22072854]. [PubMed Central: PMC3208367].

24. Schwartz-Cornil I, Benureau Y, Greenberg H, Hendrickson BA, Cohen $\mathrm{J}$. Heterologous protection induced by the inner capsid proteins of rotavirus requires transcytosis of mucosal immunoglobulins. $J \mathrm{Vi}$ rol. 2002;76(16):8110-7. doi: 10.1128/jvi.76.16.8110-8117.2002. [PubMed: 12134016]. [PubMed Central: PMC155125].

25. Garcia Sanchez Mdel V, Gonzalez R, Iglesias Flores E, Gomez Camacho F, Casais Juanena L, Cerezo Ruiz A, et al. Diagnostic value of fecal calprotectin in predicting an abnormal colonoscopy. Med Clin (Barc). 2006;127(2):41-6. doi: 10.1157/13090002. [PubMed:16801001]

26. Asano M, Komiyama K. Polymeric immunoglobulin receptor. J Oral Sci. 2011;53(2):147-56. doi: 10.2334/josnusd.53.147. [PubMed: 21712618].

27. İlhan N. Gut microbiota and metabolism. J Med Biochem. 2018. doi: 10.14744/ijmb.2018.92400.

28. Sandra VL, Martin B, Daniel T, Robert B, François B, Annaïg L. Dietary protein and amino acid supplementation in inflammatory bowel disease course: What impact on the colonic mucosa? Nutrients. 2017;9(3):310. doi: 10.3390/nu9030310. [PubMed: 28335546]. [PubMed Central: PMC5372973].

29. Marchesi JR, Holmes E, Khan F, Kochhar S, Scanlan P, Shanahan $\mathrm{F}$, et al. Rapid and noninvasive metabonomic characterization of inflammatory bowel disease. J Proteome Res. 2007;6(2):546-51. doi: 10.1021/pr060470d. [PubMed: 17269711].

30. De Preter V. Metabolomics in the clinical diagnosis of inflammatory bowel disease. Dig Dis. 2015;33(1):2-10. doi: 10.1159/000437033. [PubMed: 26368862].

31. Born P, Bauch C, Ulm K, Kamereck K, Classen M, Scheppach W. Fecal bacterial activity in symptomatic carbohydrate malabsorption: effect on the fecal short-chain fatty acid ratio. $Z$ Gastroenterol. 2000;38(8):623-6. doi: 10.1055/s-2000-7512. [PubMed: 11031785].

32. Dong YR, Fei P, Han Y, Guo L. Characterization of fecal microbiota, short-chain fatty acids and lactic acid concentrations in 5 - 8-year-old children with cow milk protein allergy. Iran J Pediatr. 2018;28(4). doi: 10.5812/ijp.64638.

33. Nistal E, Caminero A, Vivas S, Ruiz de Morales JM, Saenz de Miera LE, Rodriguez-Aparicio LB, et al. Differences in faecal bacteria populations and faecal bacteria metabolism in healthy adults and celiac disease patients. Biochimie. 2012;94(8):1724-9. doi: 10.1016/j.biochi.2012.03.025. [PubMed: 22542995].

34. Canani RB, Costanzo MD, Leone L, Pedata M, Meli R, Calignano A. Potential beneficial effects of butyrate in intestinal and extraintestinal diseases. World J Gastroenterol. 2011;17(12):1519-28. doi: 10.3748/wjg.v17.i12. [PubMed: 21472114]. [PubMed Central: PMC3070119].

35. Li L, Huang D, Nevin A, Fei P, Guo L. Fecal microbiota, lactic acid and short chain fatty levels of infants following rotavirus infection revealed by illumina miseq high-throughput sequencing and HPLC method.Jundishapur J Microbiol. 2019;12(6). doi: 10.5812/jjm.68389.

36. De Preter V, Machiels K, Joossens M, Arijs I, Matthys C, Vermeire S, et al. Faecal metabolite profiling identifies medium-chain fatty acids as discriminating compounds in IBD. Gut. 2015;64(3):447-58. doi: 10.1136/gutjnl-2013-306423. [PubMed: 24811995].

37. Garner CE, Smith S, de Lacy Costello B, White P, Spencer R, Probert CS, et al. Volatile organic compounds from feces and their potential for diagnosis of gastrointestinal disease. FASEB J. 2007;21(8):1675-88. doi: 10.1096/fj.06-6927com. [PubMed: 17314143]. 